Metal-Catalyzed

Asymmetric

Synthesis and

Stereoselective

Reactions

\section{1,4-Rhodium-Silicon Shift in an Enantioselective Synthesis of Indanols}

Key words

1,4-silicone shift

indanols

rhodium<smiles>[R18]c1ccccc1C1([R7])CC([R3])(O)C1</smiles>

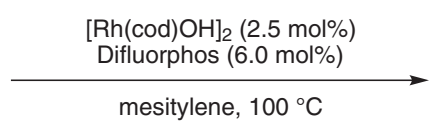<smiles>[R7][C@@]1(O)C[C@@]([R7])(C[Hg][10BH2])c2ccccc21</smiles>

$\mathrm{SiR}_{3}{ }_{3}=\mathrm{TMS}, \mathrm{SiMe}_{2} \mathrm{Bn}, \mathrm{SiMe}{ }_{2} \mathrm{Ph}, \mathrm{SiMe}_{2} \mathrm{HC}=\mathrm{CH}_{2}$, $\mathrm{SiMe}_{2} \mathrm{CH}_{2} \mathrm{HC}=\mathrm{CH}_{2}$, TES $\mathrm{R}^{2}=\mathrm{Me}, \mathrm{CH}_{2} \mathrm{OBn}, \mathrm{Ph}$ $\mathrm{R}^{3}=\mathrm{Et}, t-\mathrm{Bu}, 4-\mathrm{ClC}_{6} \mathrm{H}_{4}$, 2-thiophenyl, vinyl

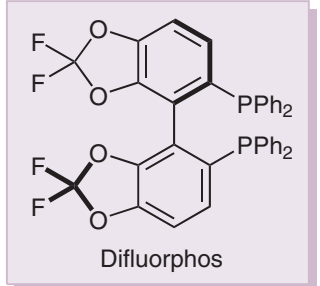
from $1.2: 1$ to $20: 1$ $82-99 \%$ ee

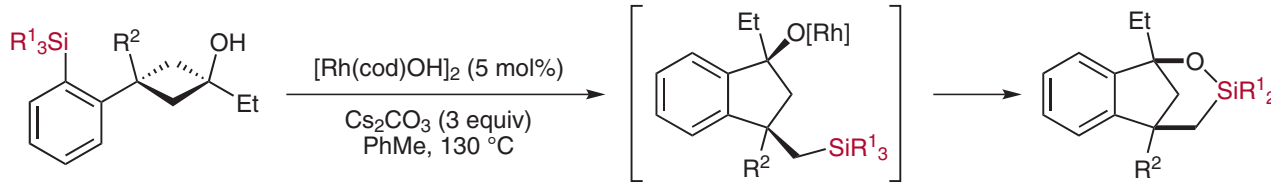

$\mathrm{SiR}_{3}^{1}=\mathrm{TMS}, \mathrm{SiMe}_{2} \mathrm{Bu}, \mathrm{SiMe}_{2} i-\mathrm{Pr}$ $\mathrm{SiR}_{2}^{1}=\mathrm{SiMe}_{2}$, SiMeBu, SiMei-Pr $\mathrm{R}^{2}=\mathrm{Me}, \mathrm{CH}_{2} \mathrm{OBn}, \mathrm{Ph}$

Mechanistic proposal:

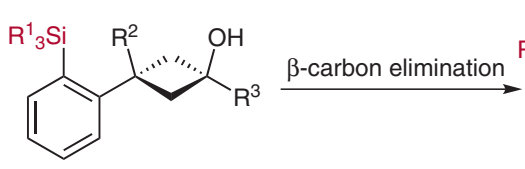<smiles></smiles>

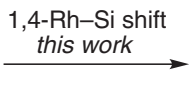<smiles>[R3]CC([R])(CC([R])=O)c1ccccc1[InH]</smiles><smiles>[R18][SiH2]c1cccc2c1[C@@]([R7])(C)C[C@]2([R9])O</smiles>

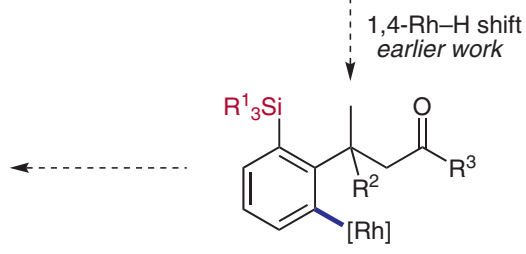

Significance: The tendency of rhodium and palladium catalysts to undergo 1,4-shifts from alkyl or vinyl to aryl positions is a well-documented phenomenon (see Review). In contrast to their earlier work (Angew. Chem. Int. Ed. 2009, 48, 6320), the authors describe a 1,4-rhodium-silicon shift. This strategy is superior to the rhodium-hydrogen shift in the sense that functionality is introduced at the alkyl position, which can be easily further modified.

Review: F. Shi, R. C. Larock Top. Curr. Chem. 2010, 292, 123-164.

SYNFACTS Contributors: Mark Lautens, Jane Panteleev Synfacts 2011, 3, 0277-0277 Published online: 16.02.2011 DoI: 10.1055/s-0030-1259478; Reg-No.: L01011SF
Comment: Several selectivity issues were addressed by this work. High enantioselectivity in $\beta$-carbon cleavage could be achieved for the trans products using Difluorphos or Dolefin ligands. The trans/cis selectivity of the ketone addition could be modulated by the solvent and the ligand used. Olefin ligands were selective for silicon versus hydrogen migrations, with phosphine ligands favoring hydrogen shifts. Tricyclic products could also be formed, possibly from a rhodium-catalyzed Si-alkyl insertion. The silicon group could easily be converted into an alcohol, and vinyl or allyl silyl groups could also participate in the migration. 